\title{
Blood Viscosity Response to Aerobic Exercise in Type 2 Diabetic Men
}

\author{
TAHA A. ELBRAGILY, M.Sc.*; NAGWA H. BADR, Ph.D.*; NAGLAA M. ELSAYED, M.D.** and \\ SAMAH M. ISMAIL, Ph.D.*
}

The Department of Physical Therapy for Cardiovascular Respiratory Disorders \& Geriatrics, Faculty of Physical Therapy* and The Department of Internal Medicine, Faculty of Medicine**, Cairo University

\begin{abstract}
Background: Cardiovascular complications are very common in diabetic patients. Type 2 diabetic patients have elevated whole blood viscosity which is associated with these vascular complications.

Aim of Study: To determine the effect of aerobic exercises on blood viscosity in type 2 diabetic patients.

Methods: Thirty type 2 diabetic men included in the study from Kasr Al-Ainy Hospital and from outpatient clinics at Faculty of Physical Therapy Cairo University. Their mean \pm SD age, weight, height, BMI and HbAlc were $47.83 \pm 3.5$ years, $91.8 \pm 5.82 \mathrm{~kg}, 175.2 \pm 6.4 \mathrm{~cm}, 29.69 \pm 2.1\left(\mathrm{~kg} / \mathrm{m}^{2}\right)$ and $7.15 \pm 0.63 \%$ respectively. Whole blood viscosity was evaluated before and after the training program. All patients performed moderate aerobic exercise $(65 \%-75 \%)$ in the form of treadmill exercise program 3 sessions per week for 8 weeks, the duration of the session was about 45 minutes and consist of warming up phase of slow walking on treadmill for 5 minutes (10\%:20\%), training phase 35 minutes and cooling down for 5 minutes (10\%:20\%).
\end{abstract}

Results: There was a significant decrease in the total blood viscosity post-treatment and the percent of change was $4.56 \%$.

Conclusion: Aerobic exercise is a good way to reduce blood viscosity in patients with type 2 diabetes mellitus and this can help control vascular complications.

Key Words: Aerobic exercise - Whole blood viscosity Diabetes mellitus - Cardiovascular complications.

\section{Introduction}

DIABETES is a group of metabolic diseases characterized by hyperglycemia resulting from defects in insulin secretion, insulin action, or both. The chronic hyperglycemia of diabetes is associated with long-term damage, dysfunction, and failure of different organs, especially the eyes, kidneys, nerves, heart, and blood vessels [1].

Correspondence to: Dr. Taha A. Elbragily, E-Mail: tahaahmed.ta218@gmail.com
Diabetes is a disease that is strongly associated with both microvascular and macrovascular complications, including retinopathy, nephropathy, and neuropathy (microvascular) and ischemic heart disease, peripheral vascular disease, and cerebrovascular disease (macrovascular), resulting in organ and tissue damage in approximately one third to one half of people with diabetes [2].

Hyperglycaemia damages blood vessels through a process called "atherosclerosis", or clogging of arteries. This narrowing of arteries can lead to decreased blood flow to heart muscle (causing a heart attack), or to brain (leading to stroke), or to extremities (leading to pain and decreased healing of infections) [3]

The risk of acute myocardial infarction and cardiovascular death increases with elevations in whole blood viscosity. Some studies confirmed that whole blood viscosity is a predictor of cardiovascular events. In addition, marked hemorheological impairments were observed in diabetic patients and a high whole blood viscosity is associated with increased insulin resistance [4].

Exercise training, acute exercise and hypoxic exposure are known to modulate red blood cell volume/hematocrit (Hct). While acute exercise increases Hct, exercise training usually decreases it, which may result in large blood viscosity changes [5].

Physical activity reduces the risk of developing T2DM and risk reductions are observed with as little as $150 \mathrm{~min} /$ week of moderate aerobic exercise and/or at least $90 \mathrm{~min} /$ week of vigorous aerobic exercise that means 30 minutes of moderate exercise per day can help reducing the risk of developing T2DM [6]. Regular exercise improves glycemic 
control in all forms of diabetes. Insulin resistance is the major cause of hyperglycemia in T2DM and physical exercise is the best way to reduce insulin resistance [7].

\section{Patients and Methods}

\section{I- Patients:}

Thirty type 2 diabetic men were included in this study. They were recruited from outpatient clinics at Kasr Al-Ainy Hospital and from outpatient clinics at Faculty of Physical Therapy Cairo University. From December 2018 to August 2019 and the study was conducted at outpatient clinics at Faculty of Physical Therapy, Cairo University. All the patients were subjected to complete clinical evaluation (including careful history taking, vital signs and random blood glucose measure before every session using hand held glucometer).

All patients received a complete explanation of the objectives and procedures of the study. The Ethics Committee of Faculty of Physical Therapy, Cairo University, Egypt n (P.T.REC/012/001151) reviewed and approved this study. All the patients performed moderate $(65 \%: 75 \%)$ aerobic exercises in the form of treadmill exercise program. And blood viscosity was measured before and after 8 weeks of training program.

Patients were chosen under the following criteria: Men patients had type 2 diabetes mellitus with duration from 3 to 5 years, their age ranged from 40 to 60 years old, they were on oral hypoglycemic drugs at the same dose.

Their BMI ranged from 30 to $34.9 \mathrm{~kg} / \mathrm{m}^{2}$ (class1 obesity), their $\mathrm{HbA} 1 \mathrm{c}$ ranged from $6.5 \%$ to $8.0 \%$ and all patients were clinically and medically stable when attending the study.

Patients with one of the following criteria were excluded from the study: Unstable cardiovascular problems, previous thrombotic events, Type $1 \mathrm{DM}$, patients on insulin therapy or using drugs that affect blood viscosity, chronic chest disease, musculoskeletal diseases which may affect their physical activity, smokers and Auditory and visual problems.

\section{II- Instrumentations:}

\section{A- Evaluative equipment and tools:}

- Viscometer U tube (Fiber Glass, Egypt), thermostatically controlled glass water bath and stop watch for measuring blood viscosity.

- Pulse oximeter equipment ChoiceMMed manufactured in (Germany) was used to measure resting heart rate and $\mathrm{SPO} 2$.
- Weight and height scale (ZT-120 Health scale, china) was used to measure the weight and height of each patient to determine their BMI.

- Hand held glucometer: Used to measure random blood glucose before each exercise session.

\section{B- Treatment equipment and tools:}

Training Treadmill 2800-Phantom AC MOTOR manufactured in (China) used for training.

\section{Procedures:}

\section{Evaluation procedures:}

Patient history was carefully taken to collect data about his general condition, physical activity and current medication, all medical and demographic data of patients was collected and the role of physical therapy importance in improving their life was explained.

Determine resting heart rate (HRrest) and maximum heart rate (HRmax) to determine the target heart rate used in exercise for each patient.

HRmax $=220$-age. Target heart rate can be calculated as a range of $65 \%-75 \%$ intensity according to Karvonen method.

$\mathrm{THR}=[($ HRmax - HRrest $) \mathrm{X} \%$ intensity $]+$ HRrest $[\mathbf{8}]$

\section{Laboratory measurements:}

The assessment was carried out at Al-Ansary Laboratory (Cairo, Egypt), Venous blood samples $(5 \mathrm{ml})$ were collected from each patient before and after 8 weeks of treatment, the samples were collected in anticoagulant-free tubes (EDTA K3).

The assessment of blood viscosity was carried out using $\mathrm{U}$ tube viscometer, thermostatically controlled glass water bath and stop watch. The $u$ tube viscometer was placed in the bath at $37^{\circ} \mathrm{c}$, then the descending limb of viscometer is filled with distilled water, with stop watch in hand, the blood was allowed to run through the descending capillary to the lower reservoir bulb, stop watch was started as the blood level passes the lower mark and stopped when it reaches the upper mark and the time taken was recorded.

\section{Treatment procedures:}

Random blood glucose was measured for all patients before every session to ensure that their blood glucose level with in normal average and it is safe to do exercise.

Patients performed aerobic exercise at moderate intensity (65\%:75\%) which was determined by Karvonen method as mentioned before. 
The total duration was about 45 minutes and consist of warming up phase of slow walking on treadmill for 5 minutes, training phase 35 minutes and cooling down for 5 minutes. And it was done for three days per week for 8 weeks.

A- Warming up exercise: The subject started the exercise session with warming up exercise at $10 \%$ to $20 \%$ of their heart rate reserve for 5 mins to allow for conditioning of the body for the exercise [9].

$B$ - Active exercise phase: After warming up, continuous running was performed started by walking increased gradually in speed every $2 \mathrm{mins}$ [10] to reach intensity of $65 \%$ to $75 \%$ of the heart rate reserve of the patient. The running period was $15 \mathrm{mins}$ for the first session, and every session 2 mins were added to the running period in a stepwise manner until the running period reached 30mins [11]

$C$ - Cool down exercise: At the end of each session, there was a cool-down period consisting of slow running and stretching for $5 \mathrm{mins}$ to avoid postural hypotension and venous pooling of blood (Beni et al., 2013) [11].

\section{Statistical analysis:}

Descriptive statistics in form of mean, standard deviation, minimum, maximum and rang values were conducted for subject characteristics. Normal distribution of data was checked using the ShapiroWilk test. Paired $t$-test was conducted for comparison of total blood viscosity between pre and posttreatment. The level of significance for all statistical tests was set at $p<0.05$. All statistical analysis was conducted through the Statistical Package for Social Studies (SPSS) version 22 for windows (IBM SPSS, Chicago, IL, USA).

\section{Results}

\section{Subject characteristics:}

Thirty patients with type 2 diabetes participated in this study. Table (1) showed the subjects' characteristics of the study group.

Table (1): Subject characteristics of the study group.

\begin{tabular}{lclll}
\hline & \multicolumn{4}{c}{ Mean \pm SD } \\
\hline Age (years) & $47.83 \pm 3.5$ & 41 & 55 & 14 \\
Weight $(\mathrm{kg})$ & $91.8 \pm 5.82$ & 82 & 110 & 28 \\
Height $(\mathrm{cm})$ & $175.2 \pm 6.4$ & 165 & 187 & 22 \\
BMI $\left(\mathrm{kg} / \mathrm{m}^{2}\right)$ & $29.69 \pm 2.1$ & 26.3 & 34.6 & 8.31 \\
HbAlc & $7.15 \pm 0.63$ & 6 & 8.4 & 2.4 \\
\hline
\end{tabular}

SD: Standard Deviation.

\section{Effect of treatment on total blood viscosity:}

There was a significant decrease in the total blood viscosity post-treatment compared with that pre-treatment $(p<0.001)$. The percentage of decrease in total blood viscosity was $4.56 \%$ (Table 2), Fig. (1).

Table (2): Mean total blood viscosity pre and post-treatment of the study group.

\begin{tabular}{|c|c|c|c|c|c|c|}
\hline & $\begin{array}{c}\text { Pre } \\
\text { Mean } \pm \text { SD }\end{array}$ & $\begin{array}{c}\text { Post } \\
\text { Mean } \pm \text { SD }\end{array}$ & MD & $\begin{array}{l}\% \text { of } \\
\text { change }\end{array}$ & $\begin{array}{c}t- \\
\text { value }\end{array}$ & $\begin{array}{c}p- \\
\text { value }\end{array}$ \\
\hline $\begin{array}{l}\text { Total blood } \\
\text { viscosity (cp) }\end{array}$ & $5.48 \pm 0.65$ & $5.23 \pm 0.67$ & 0.25 & 4.56 & 8.1 & 0.001 \\
\hline $\begin{array}{l}\text { SD : Stanc } \\
\text { MD : Mean } \\
p \text {-value : Prob }\end{array}$ & $\begin{array}{l}\text { lard Deviatio } \\
\text { Difference. } \\
\text { ability value. }\end{array}$ & & & & & \\
\hline
\end{tabular}

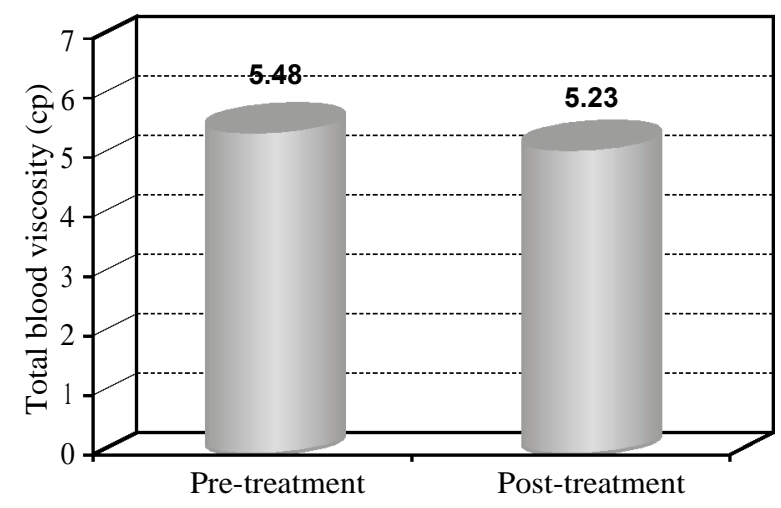

Fig. (1): Mean total blood viscosity pre and post-treatment of the study group.

\section{Discussion}

The present study was conducted to measure the effect of aerobic exercises on blood viscosity in type $2 \mathrm{DM}$. Thirty diabetic men were recruited from outpatient clinics at Qasr Al-Ainy Hospital and from outpatient clinics at Faculty of Physical Therapy, Cairo University. All the patients were evaluated before and after treatment by using blood sample analysis of blood viscosity.

The findings of the present study indicated significant decrease in the total blood viscosity post-treatment in the study group compared with that pre-treatment $(p=0.0001)$. And the percentage of change was $4.56 \%$.

The results of the current study agreed with the findings of (Romain et al.) [12] meta-analysis who conduct his study to determine the effects of exercise on blood rheology. 11 studies with 175 people were found and included in this meta-analysis. The overall results confirm that hematocrit, whole blood viscosity and red cell aggregation are decreased after training. 
Simmonds et al., [13] demonstrated that moderate-intensity treadmill walking for $120 \mathrm{~min} / \mathrm{wk}$ significantly decreased RBC aggregation which is one of the main determinants of blood viscosity (that means reduction in blood viscosity) in older women with type 2 diabetes. Interestingly, no changes in anthropometry (e.g., body mass index) were observed during the training period, suggesting that hemorheology improved in the diabetic patients due to mechanisms independent of reduced adiposity and decreased hyperglycemia. It is likely that plasma factors may explain, in part, the reduced $\mathrm{RBC}$ aggregation following exercise. Which concided with the results of the current study.

The results of the current study also consistent with the findings of (E. Nawara et al.) [14]. She investigated the effect of aerobic training in the form of treadmill running program 3 times per week for 8 weeks on the blood viscosity in diabetic and hypertensive women. She reported a decrease of $20 \%$ in blood viscosity in the study group compared to $7.2 \%$ decrease in the control group.

The results of the current study also come in line with with the findings of (Sandor et al.) [15] who demonstrated that Regular physical training improved the exercise tolerability of patients with ischemic heart disease and decreased hematocrit and blood viscosity which reduce cardiovascular risk.

On the other hand, the results of this study contradicted the study of (Connes et al.) [16] who reported in their review that 8 weeks of aerobic exercise have significant effect on decreasing plasma viscosity and have no effect on whole blood viscosity. He also reported that 12 week or more of aerobic exercise have significant effect on both plasma and blood viscosity.

\section{Conclusion:}

Regular aerobic exercises can reduce blood viscosity on the long term, so that cardiovascular complications can be prevented or at least can be delayed. Diabetic patients should do moderate aerobic exercises to control micro vascular and macro vascular complications.

\section{References}

1- American Diabetes Association: Diagnosis and Classification of Diabetes Mellitus. Diabetes Care Jan., 37 (Supplement 1): S81-S90, 2014.

2- W. TODD CADE: Diabetes-Related Microvascular and Macrovascular Diseases in the Physical Therapy Setting
Journal of American Physical Therapy Association, 88 (11): 1322-35, 2008.

3- World Health Organization: Global report on diabetes. [online] Available at: https://www.who.int/diabetes/globalreport/en/, 2016.

4- YING LI, XIU-XIA TIAN, TIEMIN LIU and RUI-TAO WANG: Association between whole blood viscosity and arterial stiffness in patients with type 2 diabetes mellitus. Springer. 10.1007/s12020-014-0451-3, 2014.

5- PICHON, AURÉLIEN P., CONNES, PHILIPPE, and ROBACH and PAUL: 'Effects of Acute and Chronic Hematocrit Modulations on Blood Viscosity in Endurance Athletes', 1 Jan. 115-23, 2016.

6- KÖNIG D. and BERG A.: Bewegung als Therapie bei Diabetes mellitus Typ 2 [Physical exercise as treatment of type 2 diabetes mellitus]. Internist (Berl), 53 (6): 67887. doi: 10.1007/s00108-011-2936-y, 2012.

7- GOODPASTER B., DeLANY J., OTTO A., KULLER L., VOCKLEY J., SOUTH-PAUL J., THOMAS S., BROWN J., McTIGUE K., HAMES K., LANG W. and JAKICIC J.: Effects of Diet and Physical Activity Interventions on Weight Loss and Cardiometabolic Risk Factors in Severely Obese Adults. JAMA, 304 (16): p. 1795, 2010.

8- KARVONEN J. and VUORIMAA T.: Heart Rate and Exercise Intensity During Sports Activities. Sports Medicine, 5: 303-11 https://doi.org/10.2165/00007256198805050-00002, 1988.

9- HILL E., ZACK E., BATTAGLINI C., VIRU M., VIRU A., et al.: Exercise and circulating cortisol levels: The intensity threshold effect. Journal of Endocrinological Investigation, 31 (7): 587-91, 2008.

10- KETEYIAN S.J.: Graded exercise testing and exercise prescription. In J. K. Ehrman, P. M. Gordon, P. S. Visich andS. J. Keteyian (Eds.), Clinical Exercise Physiology (pp. 61-88): Human Kinetics, 2013.

11- BENI M.A., AKBARI Z., ASSARZADEH M. and AZIZBEIGI K.: The effect of selected aerobic training on serum immunoglobulin levels and testosterone and cortisol hormones in young men. International Journal of Sport Studies, 3 (9): 956-62, 2013.

12- ROMAIN A.J., BRUN J.F., VARLET MARIE, EMMANUELLE and RAYNAUD De MAUVERGER: Effects of exercise training on blood rheology: A meta-analysis. Clinical Hemorheology and Microcirculation, 10.3233/CH2011-1469, 2011.

13- SIMMONDS M.J., MINAHAN C.L., SERRE K.R., GASS G.C., MARSHALL-GRADISNIK S.M., HASELER L.J. and S. SABAPATHY: Preliminary findings in the heart rate variability and haemorheology response to varied frequency and duration of walking in women 65-74 yr with type 2 diabetes, Clin. Hemorheol. Microcirc., 51: 87-99, 2012.

14- NAWARA E.N., ELNAHHAS N., HASSAN Z. and KAMEL M.: 'Effect of Aerobic Training on Blood Viscosity in Hypertensive Women' Med. J. Cairo Univ., Vol. 87, No. 8, December: 5005-8, 2019.

15- SANDOR B., NAGY A., TOTH A., RABAI M., MEZEY B., CSATHO A., CZURIGA I., TOTH K. and SZABADOS 
E.: Effects of moderate aerobic exercise training on hemorheological and laboratory parameters in ischemic heart disease patients. PloS one, 9 (10): e1 10751. https:// doi.org/10.1371/journal.pone.0110751, 2014.
16- CONNES P., MICHAEL J. SIMMONDSC, JEANFREDERIC BRUND and OGUZ K. BASKURT: Clinical Hemorheology and Microcirculation, 187-199 DOI 10.3233/CH-2012-1643, 2013.

\section{تآثير التمرينات الهوائية

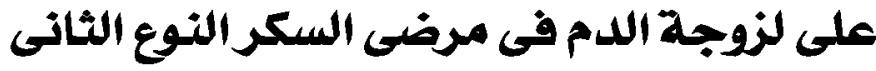

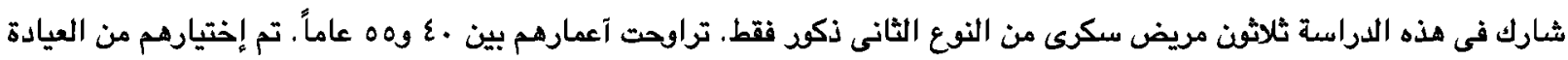

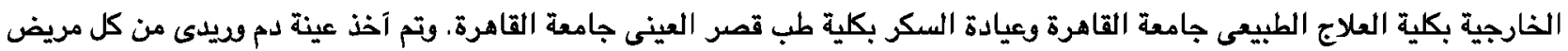

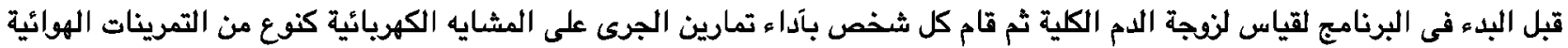

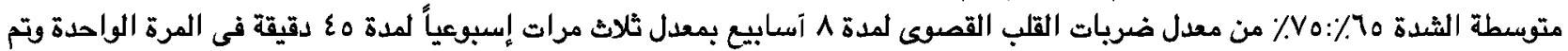

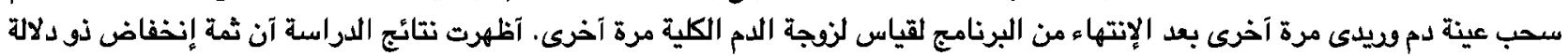

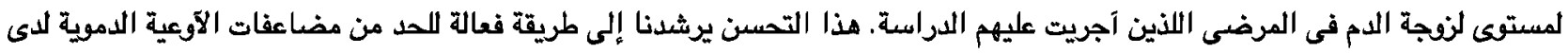

